\title{
A fase inicial de uma aula de Matemática no Ensino Exploratório na visão profissional de futuros professores
}

\section{The initial phase a Mathematics class in Exploratory Teaching in the Preservice teachers' professional vision}

\author{
Renata Viviane Raffa Rodrigues (reraffa@gmail.com) \\ Doutora em Ensino de Ciências e Educação Matemática pela Universidade Estadual de Londrina (UEL). \\ Professora da Faculdade de Ciências Exatas e Tecnologia da Universidade Federal da Grande Dourados
}

(UFGD)

\begin{abstract}
Márcia Cristina de Costa Trindade Cyrino (marciacyrino@uel.br)
Doutora em Educação pela Universidade de São Paulo (USP). Professora do Departamento de Matemática e do Programa de Pós-graduação em Ensino de Ciências e Educação Matemática da Universidade Estadual de Londrina (UEL)
\end{abstract}

\section{Resumo:}

Este trabalho, de natureza qualitativa, contou com a participação de duas turmas de futuros professores (FP) que cursaram uma disciplina específica de prática como componente curricular assente na exploração de um caso multimídia e oferecida em um curso de Licenciatura em Matemática. Nesse contexto formativo, o estudo centra-se na visão profissional desses FP sobre as ações docentes realizadas para promover o engajamento inicial dos alunos em uma aula de Matemática na perspectiva do Ensino Exploratório. A aula é contemplada no caso por meio de diferentes mídias que retratam elementos da prática de uma professora experiente no Ensino Exploratório, voltada à promoção do pensamento algébrico de alunos de um $6^{\circ}$ ano do Ensino Fundamental de uma escola pública. Esta investigação utiliza como fontes de dados as respostas escritas que os FP expressaram às questões do multimídia referentes ao vídeo analisado. Os resultados evidenciam seis aspectos, concernentes ao modo pelo qual a professora propõe e apresenta a tarefa aos alunos, que se sobressaem à visão dos FP. Além disso, na medida em que os FP conseguem perpassar diferentes dimensões de raciocínio descrição, explicação e previsão, sobre os eventos (re)conhecidos no vídeo, eles revelam perceber os significados didático-pedagógicos que subjazem tais aspectos.

Palavras-chave: Caso multimídia; Ensino Exploratório de Matemática; Engajamento dos alunos; Visão profissional de Futuros Professores.

\footnotetext{
Abstract:

This qualitative study had the participation of two classes of preservice mathematics teachers (PTs) who studied a specific discipline of practice as a curricular component based on the exploration of a multimedia case and offered in a licentiate degree in Mathematics. In this formative context, the study focuses on the professional vision of these PTs on the teaching actions carried out to promote the initial engagement of
} 
students in a Mathematics lesson from the perspective of Exploratory Teaching. The lesson is contemplated in the case through different medias that portray elements of the practice of a teacher experienced in the Exploratory Teaching, focused on the promotion of algebraic thinking of students of a 6th grade elementary school in a public school. This research uses the written responses that the PTs expressed to the multimedia questions regarding the analyzed video as data sources. The results show six aspects, concerning the way in which the teacher proposes and presents the task to the students, who stand out for the vision of the PTs. Moreover, insofar as PTs are able to pass through different dimensions of reasoning - description, explanation and prediction, about events (re)cognized in the video, they reveal the didactic-pedagogical meanings that underlie these aspects.

Keywords: Multimedia Case; Exploratory Mathematics Teaching; Student Engagement; Preservice Teachers' Professional Vision.

\section{INTRODUÇÃO}

A formação inicial de professores configura-se como o primeiro momento de formação deliberada com objetivos institucionais voltados ao desenvolvimento de capacidades e à construção de conhecimentos profissionais da docência (SILVA; GÜLLICH; FERREIRA, 2011).

Fiorentini, Nacarato e Pinto (1999) apontam que esse desenvolvimento tem um caráter pessoal, ligado às reflexões que o professor faz sobre as experiências concernentes à atividade docente. Nesse sentido, esses autores indicam que o contexto de formação precisa propor ações imaginativas e diversificadas dessas experiências, por meio de situações, tanto quanto possível, próximas da prática docente.

Entretanto, em nossa trajetória profissional como formadoras atuando no curso de Licenciatura em Matemática, as experiências educacionais relatadas pelos acadêmicos, denotam que raras são as oportunidades em que eles vivenciam, na sua formação matemática ou no Estágio de observação, práticas pedagógicas diferenciadas do ensino tradicional.

Dessa forma, entendemos que o processo de desconstrução e ressignificação das concepções docentes consolidadas na formação ambiental dos futuros professores (FP) (SILVA; GÜLLICH; FERREIRA, 2011) demandam ações de formação inicial que lhes permitam perceber e raciocinar (Van ES; SHERIN, 2002; SEIDEL; STÜRMER, 2014) 
sobre os elementos que sustentam o "ensino directo" "(PONTE, 2005), como também aqueles que se contrapõem a ele e orientam práticas pedagógicas em que o aluno desempenha um papel (inter)ativo ${ }^{2}$ no processo de aprendizagem.

Segundo esses pressupostos, este estudo desenvolve-se no âmbito da formação inicial de professores de Matemática, em uma disciplina de prática como componente curricular (BRASIL, 2001), cujo contexto formativo baseia-se na exploração de um caso multimídia que, dentre outras mídias, recorre ao vídeo para evidenciar elementos da prática docente em uma aula de Matemática na perspectiva do Ensino Exploratório. Nesse contexto, o estudo aqui apresentado foca-se na visão profissional de 36 FP sobre as ações docentes realizadas para promover o engajamento inicial dos alunos em uma aula de Matemática na perspectiva do Ensino Exploratório.

Nas seções que seguem, apresentamos alguns dos elementos que fundamentam o presente estudo, referentes à proposição e apresentação da tarefa no Ensino Exploratório na perspectiva dialógica e à visão profissional do professor na análise de vídeos. Posteriormente, descrevemos o contexto e o encaminhamento metodológico desta pesquisa, os seus resultados e terminamos com algumas conclusões.

\section{A PROPOSIÇÃO E APRESENTAÇÃO DA TAREFA NO ENSINO EXPLORATÓRIO}

No Ensino Exploratório, aluno e professor participam dialogicamente do processo de ensino e de aprendizagem (MESTRE; OLIVEIRA, 2012; CYRINO; OLIVEIRA, 2016). Essa inter-relação está pautada em elementos baseados na Inquiry based learning (CHAPMAN; HEATER, 2010; ARTIGUE; BLOMHØJ, 2013; CHAPMAN, 2013) na perspectiva dialógica (WELLS, 2004) em que os alunos são convidados e incentivados pelo professor a comunicar, questionar, refletir e colaborar (OLIVEIRA; CYRINO, 2013; CYRINO; OLIVEIRA, 2016).

\footnotetext{
${ }^{1}$ Para Ponte (2005) o ensino directo é orientado pela transmissão unidirecional, isto é, o professor fornece informações para o aluno por que acredita que ele aprende ouvindo. Outras designações encontradas na literatura da área são ensino transmissivo, puramente expositivo, ensino tradicional (ZABALA, 1998), típica aula de matemática (D’AMBRÓSIO, 1989), educação bancária (FREIRE, 1996).

2 De acordo com Góes (2000, p. 25) o conhecimento não se constitui a partir de recursos puramente individuais, isolados dos instrumentos de mediação social, por isso "o sujeito não é passivo nem apenas ativo: é interativo".
} 
Com base nessa perspectiva, a aula parte de tarefas matemáticas desafiadoras (STEIN et. al., 2008) que vão além da aplicação de técnicas para resolvê-las. As tarefas são intencionalmente selecionadas ou elaboradas pelo professor tendo em vista o envolvimento dos alunos em situações que os exijam "desenvolver conexões com os significados matemáticos" (STEIN; SMITH, 2009, p. 23), pautar-se neles para construir estratégias de resolução diversificadas, discuti-los e legitimá-los entre os pares e coletivamente.

Para tanto, a dinâmica da aula é organizada sucessivamente nas quatro fases denominadas: Proposição e apresentação da tarefa; Desenvolvimento da tarefa; Discussão coletiva da tarefa; e Sistematização, cujo desencadeamento inicial, previsto na proposição e apresentação da tarefa, ganha ênfase neste trabalho, por se tratar de uma maneira de mobilizar a iniciativa dos alunos quanto à resolução da tarefa e à participação no processo de construção conjunta de conhecimento na aula.

Esse encaminhamento da aula visa à promoção de oportunidades de aprendizagem, entendidas por Hiebert (2003) como condições propiciadas aos alunos que lhes favoreçam o envolvimento em tarefas que lhes possibilitem aprender Matemática com compreensão. Para o autor "tal engajamento pode incluir ouvir, falar, escrever, raciocinar, e uma variedade de outros processos intelectuais" (HIEBERT, 2003 p. 10). Nessa perspectiva, a aprendizagem requer diferentes formas de participação discente em sala de aula e, por conseguinte, o engajamento dos alunos destaca-se como um elemento importante ao seu movimento (WELLS, 2004).

Apoiadas principalmente na literatura assente na perspectiva dialógica, descrevemos esse engajamento como o empenho ou responsabilidade manifestada no desenvolvimento de uma tarefa na medida em que ela se torna desafiante ou importante ao sujeito (WELLS, 2004; CHAPMAN, 2013). Além disso, estar engajado com a tarefa ou com a aula significa conectar-se diretamente com o objeto do conhecimento por meio de um posicionamento de inquiry, ou seja, "um posicionamento em relação a experiências e ideias - uma disposição para pensar sobre (ter curiosidade sobre), fazer perguntas e procurar compreender, pela via da colaboração com os outros, na tentativa de construir respostas para elas" (WELLS, 2004, p. 121, grifo nosso). 
Wells (2002) sugere que as experiências anteriores dos estudantes podem ser suscitadas por meio de questionamentos sobre novas informações apresentadas a eles. Essa estratégia é a base para conhecer "as ideias que os alunos trazem espontaneamente para o tópico" (WELLS, 2002, p. 13). No entanto, Wells (2002) enfatiza que somente acessar essas informações não significa construir conhecimentos sobre o assunto, por isso elas precisam ser articuladas às experiências anteriormente mobilizadas, exploradas por processos dialógicos de inquiry que envolvem a sua discussão conjunta e aperfeiçoamento, para então serem transformadas em conhecimento.

Comumente, não é habitual dedicar um tempo da aula para promover o engajamento dos alunos, mas no Ensino Exploratório na perspectiva dialógica, esse processo não é visto como algo que só se manifesta espontaneamente, ficando dependente exclusivamente do aluno. Na primeira fase da aula no Ensino Exploratório, “o professor tem de garantir a apropriação da tarefa pelos alunos e promover sua adesão, de modo que a sua atividade matemática venha a se desenvolver" (CYRINO; OLIVEIRA, 2016, p. 24), bem como os organiza em pequenos ${ }^{3}$ grupos, oferece recursos e esclarece o que lhes é esperado na resolução da tarefa e na aula. Além de informações pontuais sobre o enunciado da tarefa, o professor explica qual será o seu papel na fase de desenvolvimento da tarefa e o tempo de duração da mesma. Tais ações são entendidas como uma forma de oferecer condições ao engajamento dos alunos com a tarefa, com os pares e com a dinâmica da aula (OLIVEIRA; MENEZES; CANAVARRO, 2013; CYRINO; TEIXEIRA, 2016).

Considerando que o desempenho dessas ações orienta-se pelas razões docentes que a elas subjazem, entendemos que o processo de percebê-las, raciocinar sobre o seu conteúdo e explicitá-las, revela-se importante à aprendizagem profissional de FP de Matemática.

\section{A ANÁllSE DE VÍdEOS E A VISÃo PROFISSIONAL DO PROFESSOR}

\footnotetext{
${ }^{3}$ Geralmente grupos de dois a quatro alunos dependendo do número de alunos da turma e do ambiente físico da sala de aula.
} 
O vídeo tem sido utilizado como uma maneira promissora de desenvolver um processo fundamental na formação inicial de professores - a reconexão entre prática e teoria (BLOMBERG et al., 2013). As possibilidades digitais do vídeo de representação da complexidade de interações de sala de aula e de assisti-las mais de uma vez e com objetivos distintos, têm apontado o potencial deste recurso na compreensão e explicitação dos aspectos que oferecem significados à prática pedagógica (Van ES; SHERIN, 2002; SANTAGATA; ZANNONI; STIGLER, 2007; BLOMBERG et al., 2013).

Os resultados do estudo de Sherin e Van Es (2009) sugerem que análise de vídeos pode promover o desenvolvimento da visão profissional do professor. Segundo van Es e Sherin (2002) este conceito consiste na capacidade de perceber (to notice) e interpretar (interpret) aspectos relevantes de situações de sala de aula. Processos que, por sua vez, podem ser descritos pelo (re)conhecimento do que é importante no evento de sala de aula e pela (re)construção de significados sobre o que está acontecendo, por meio do raciocínio com base no que se sabe sobre a situação analisada (van ES; SHERIN, 2002; SHERIN, 2007; SHERIN; van ES, 2009).

Várias pesquisas têm apresentado resultados empíricos importantes sobre as formas que os professores raciocinam sobre os eventos com base em seu conhecimento profissional sobre o ensino e a aprendizagem dos alunos (SANTAGATA; ZANNONI; STIGLER, 2007; KERSTING et al., 2010; BORKO et al., 2011). A partir dos resultados das investigações qualitativas concernentes a essa temática, Seidel e Sturmer (2014) destacam a descrição, a explicação e a previsão como três aspectos inter-relacionados (SCHÄFER; SEIDEL, 2015), mas caracterizados como distintas formas de raciocínio. A partir de uma pesquisa de abordagem quantitativa empírica, desenvolvida na formação inicial de professores, essas autoras testaram essa estrutura e obtiveram resultados que as permitiram conceituá-la teoricamente e discutir a sua utilização orientada para o ensino e avaliação formativa dos futuros professores (SEIDEL; STURMER, 2014).

Nesse sentido, a descrição consiste na capacidade de distinguir e relatar precisamente os aspectos relevantes dos componentes de ensino e de aprendizagem focalizados. Ela se mostrou um suporte importante à explicação ou previsão. A 
explicação refere-se à capacidade de mobilizar o que se sabe para raciocinar sobre eventos sala de aula, ligando-os ao conhecimento que se tem sobre os aspectos identificados. A previsão diz respeito à capacidade de, a partir do que foi observado e interpretado da situação em particular, fazer inferências sobre a aprendizagem dos alunos, prever/sugerir consequências das estratégias de ensino ou resultados de aprendizagem. Esse processo mostrou a necessidade ligar o evento percebido a aspectos mais amplos do ensino e da aprendizagem (SEIDEL; STURMER, 2014; SCHÄFER; SEIDEL, 2015).

A partir das respostas escritas de FP às questões sobre um vídeo referente à proposição e apresentação da tarefa, neste estudo, a atenção seletiva e o raciocínio baseado no conhecimento, junto aos aspectos que auxiliam na caracterização da natureza do raciocínio: descrição, explicação e previsão, são utilizados como lentes para analisar a visão profissional de futuros professores de Matemática sobre as ações docentes realizadas na fase inicial da aula para promover o engajamento dos alunos no Ensino Exploratório.

\section{CONTEXTO E ENCAMINHAMENTO METODOLÓGICO DA PESQUISA}

A primeira parte desta pesquisa-intervenção (KRAINER, 2003), de caráter qualitativo, foi desenvolvida, no segundo semestre letivo do ano de 2014, com uma turma de $15 \mathrm{FP}^{4}$, que tiveram frequência regular em uma disciplina sobre prática de ensino de Matemática no Ensino Fundamental de um curso de Licenciatura em Matemática, no Estado do Mato Grosso do Sul, Brasil, sendo a primeira autora docente responsável pela disciplina. No mesmo contexto, a segunda parte da pesquisa foi desenvolvida, no primeiro semestre letivo do ano de 2017, com outra turma de $21 \mathrm{FP}^{5}$. Dessa forma, o estudo completo contou com a participação de 36 FP. Devido a disciplina cursada pelos participantes visar à construção de oportunidades aos FP de

\footnotetext{
${ }^{4}$ Ao longo do texto esses participantes da pesquisa são indicados a partir dos setes grupos de trabalho formados (seis duplas e um trio), segundo a seguinte sequência de números ímpares: G1, G3, G5, G7, G9, G11 e G13.

${ }^{5}$ Ao longo do texto esses participantes da pesquisa são indicados a partir dos dez grupos de trabalho (9 duplas e um trio) formados, segundo a seguinte sequência de números pares: G2, G4, G6, G8, G10, G12, G14, G16, G18 e G20.
} 
(re)conhecer e compreender perspectivas inovadoras no ensino de Álgebra (Ensino Fundamental), a intervenção baseou-se na exploração do caso multimídia "Os colares". Toda a exploração do caso, com cada uma das turmas, aconteceu em 11 encontros, duas vezes por semana, com duração de 3 h e 20 min semanais.

Em uma plataforma online ${ }^{6}$, esse caso reúne diferentes mídias, que procuram evidenciar etapas da atividade profissional de uma professora experiente com o Ensino Exploratório, ligadas a uma aula voltada ao desenvolvimento do pensamento algébrico de alunos de um $6^{\circ}$ ano do Ensino Fundamental (FIGURA 1; FIGURA 2).

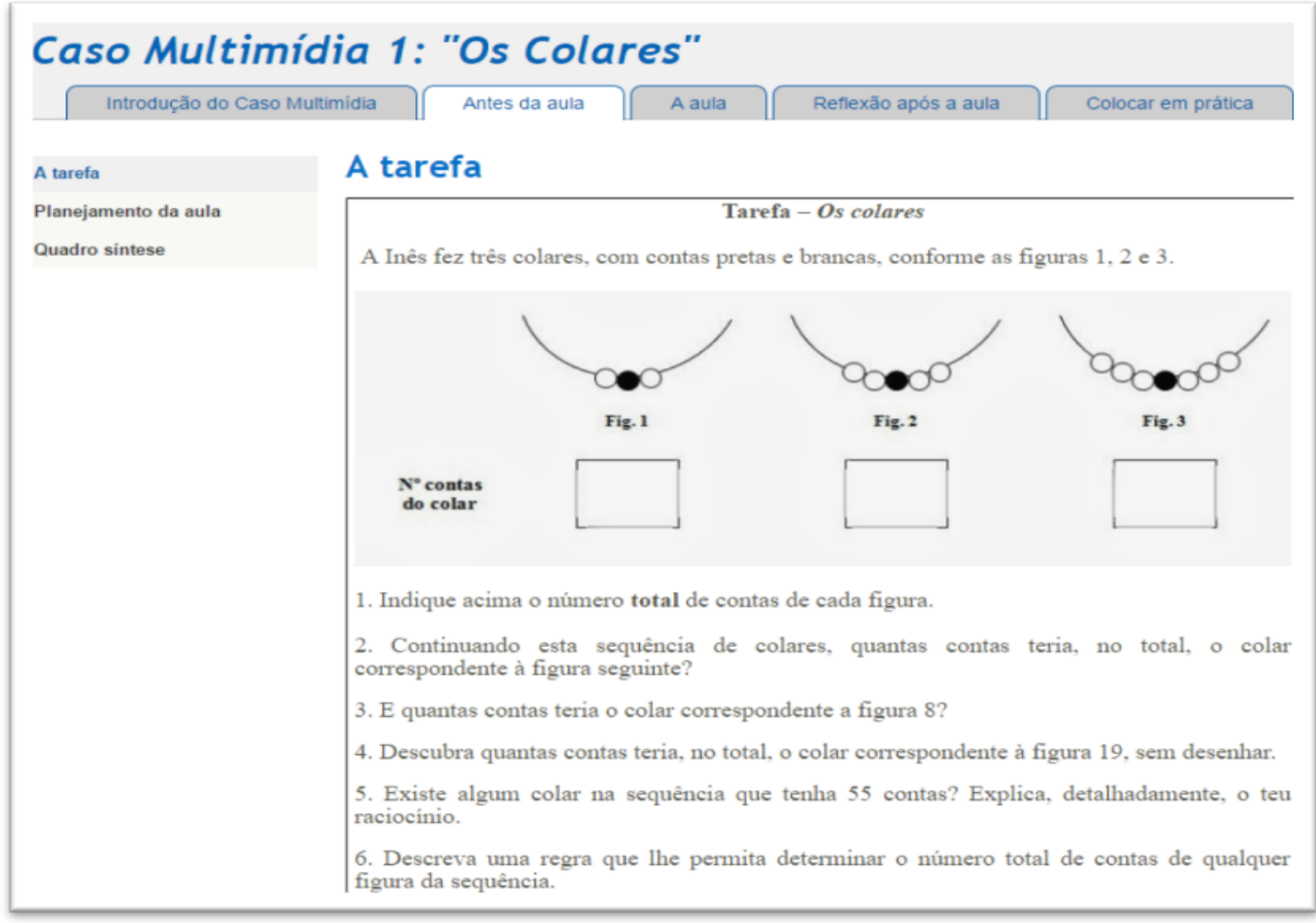

Figura 1 - Tarefa “Os colares” na Etapa Antes da aula (www.rmfp.uel.br).

\footnotetext{
${ }^{6}$ Disponível em http://rmfp.uel.br.
} 


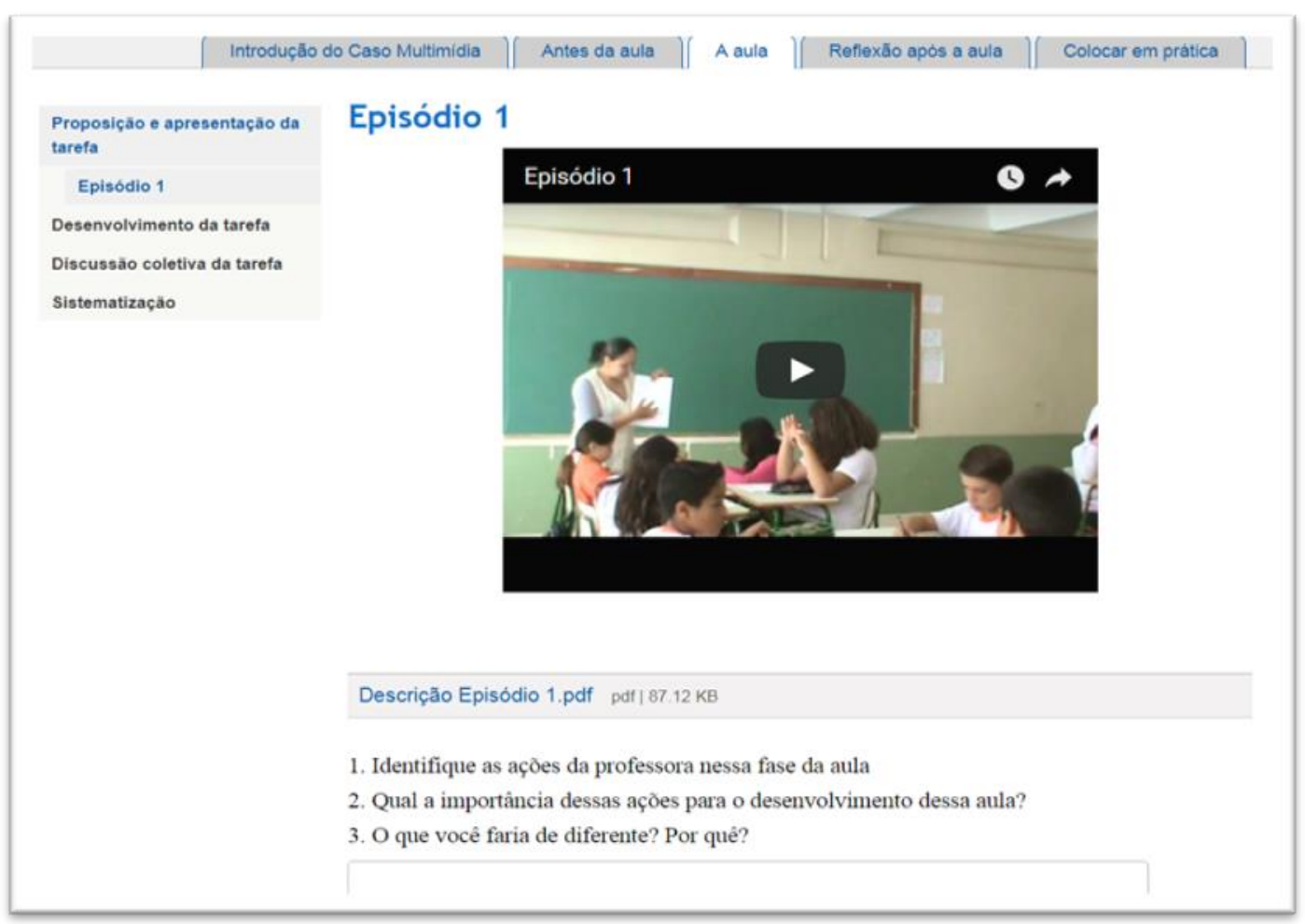

Figura 2 - Proposição e apresentação da tarefa na Etapa A aula (www.rmfp.uel.br).

Embora não seja foco desse estudo, cabe salientar que os grupos de FP, primeiro dedicavam-se para responder as questões problematizadoras apresentadas no recurso (FIGURA 2). Depois, com a turma toda, realizavam discussões fomentadas pela formadora sobre os aspectos que lhes chamaram atenção nas mídias exploradas.

Todavia, neste estudo, os dados analisados incidem apenas sobre as respostas escritas dos 17 grupos de FP das duas diferentes turmas às questões presentes no multimídia referentes ao vídeo que retrata a fase de proposição e apresentação da tarefa pela professora (FIGURA 2).

\section{PROCEDIMENTOS DE ANÁLISE DOS DADOS}

Sherin e van ES (2009) apontam que a atenção seletiva funciona como um indicador útil dos aspectos considerados relevantes no vídeo, porque evidencia as ideias que se tornaram foco principal dos professores no momento da análise. Do mesmo modo, as autoras apontam como um indicador importante - o raciocínio baseado no 
conhecimento, uma vez que este abrange os significados que são (re)construídos pelos professores sobre os aspectos que se tornam objeto de sua atenção.

Tendo em conta tais pressupostos, para análise dos dados assumimos a perspectiva interpretativa (ERICKSON, 1986) e os procedimentos de codificação de dados pautada na Teoria Fundamentada (Grounded Theory) (CHARMAZ, 2009). Com essa técnica de análise, os dados foram codificados, em um primeiro momento, em termos dos aspectos que chamaram a atenção dos FP na análise do vídeo da fase de proposição e apresentação da tarefa e, posteriormente, segundo os conhecimentos explicitados pelos FP ao raciocinarem sobre tais aspectos.

Inicialmente analisamos as respostas grupo a grupo e questão a questão, criando tópicos iniciais para identificar os aspectos que foram significativos aos FP associandoos à natureza do raciocínio mobilizado por cada grupo. Depois, os tópicos foram agrupados por semelhança, que se basearam na mesma característica/fundamento/evidência, criando um tópico sintetizador para descrevê-los e apontando os grupos que o destacaram, bem como os modos que raciocinaram sobre tal ponto de enfoque.

\section{APRESENTAÇÃO E DISCUSSÃO DOS RESULTADOS}

A partir de seis quadros, apresentamos e discutimos cada um dos aspectos da proposição e apresentação da tarefa percebidos pelos FP. Na sua primeira coluna, esses quadros contêm características/evidências com a autoria, data do encontro, mídia (Ep.1 - Episódio 1, por exemplo) e questão geradora da resposta (por exemplo: Q2 - Questão 2). Na coluna ao lado, indicamos os grupos de FP que os destacaram, acompanhados pelas letras $\mathrm{D}, \mathrm{E}$ ou $\mathrm{P}$ que representam a natureza de raciocínio (NR) que eles manifestaram: descrição (D), explicação (E) ou previsão (P). Esses quadros foram sequenciados dos aspectos mais percebidos aos menos percebidos pelos FP. 
6.1. VISÃO PROFISSIONAL DOS FP SOBRE AS AÇÕES DA PROFESSORA PARA PROMOVER O ENGAJAMENTO INICIAL DOS ALUNOS NO ENSINO EXPLORATÓRIO

Como pode ser observado no Quadro 1, o modo de organizar a atividade dos alunos, com a formação de pequenos grupos, é percebido por quase todos os FP e de diferentes maneiras por cada um deles.

Quadro 1 - Formação de grupos.

\begin{tabular}{|c|c|}
\hline Evidências & $\begin{array}{l}\text { Grupos } \\
\text { de FP e } \\
\text { NR }\end{array}$ \\
\hline $\begin{array}{l}\text { [...] dessa forma cria-se um ambiente propício à discussão } \\
\text { entre os mesmos. De modo geral, os indivíduos constroem o } \\
\text { conhecimento na medida em que buscam tirar melhor } \\
\text { proveito de suas experiências, assim a discussão em grupo } \\
\text { instiga o aluno a troca de conhecimento contribuindo para } \\
\text { a aprendizagem. (G2, } \mathrm{P}, 03 / 07 / 17 \text {, Ep. } 1 \text { - Q2). }\end{array}$ & $\begin{array}{l}\text { G1 (E), } \\
\text { G2 (P), } \\
\text { G3 (D), } \\
\text { G4 (P), } \\
\text { G5 (P), } \\
\text { G6 (D), }\end{array}$ \\
\hline $\begin{array}{l}\text { Uma boa organização é fundamental para o } \\
\text { desenvolvimento da aula, a junção novamente dos grupos } \\
\text { proporciona aos alunos a continuação da realização do } \\
\text { trabalho juntos, permitindo a troca de ideias. [...], } \\
\text { possivelmente, a forma como eles pensaram na atividade } \\
\text { anterior possa contribuir para a continuação das tarefas } \\
\text { seguintes possibilitando um conjunto de formação de ideias } \\
\text { que os ajudarão a concluir essa tarefa. (G4, } \mathrm{P}, 03 / 07 / 17, \text { Ep. } \\
1 \text { - Q2). }\end{array}$ & $\begin{array}{l}\text { G7 (D), } \\
\text { G8 (D), } \\
\text { G9 (D), } \\
\text { G10 (D), } \\
\text { G11 (D), } \\
\text { G12 (E), } \\
\text { G14 (D), } \\
\text { G16 (E), } \\
\text { G18 (D), }\end{array}$ \\
\hline
\end{tabular}




\begin{tabular}{|c|c|}
\hline $\begin{array}{l}\text { [...] em grupo os alunos expõem suas ideias e fazem uma } \\
\text { discussão sobre a tarefa e assim conseguem justificar suas } \\
\text { respostas [...]. (G5, P, 01/10/14, Ep.1 - Q2). [...] Pediria } \\
\text { para que os alunos fizessem individualmente a tarefa, assim } \\
\text { evitaria que um copiasse do outro e iria orientando nas } \\
\text { carteiras [...]. (G5, P, 29/09/14, Ep.1-Q3). }\end{array}$ & $\begin{array}{l}\text { G20 }(\mathrm{E}), \\
(\mathbf{1 6} \\
\text { grupos) }\end{array}$ \\
\hline
\end{tabular}

$\mathrm{Na}$ tentativa de compreender as razões pelas quais a professora organiza a sala para que o desenvolvimento da tarefa seja realizado em pequenos grupos, algumas explicações e previsões são elaboradas pelos FP. Os dados apresentados no Quadro 1, por um lado, evidenciam o (re)conhecimento da importância dessa forma de trabalho para a exposição e discussão de ideias entre os alunos, bem como para a mobilização de experiências anteriores, e de ambas, ao processo de construção conjunta de conhecimento (WELLS, 2002; 2004). Porém, por outro lado, também indica a preocupação de alguns FP de que nem todos os alunos participem (inter)ativamente da resolução da tarefa. Essa previsão dos FP pode estar associada à ideia de que os alunos resolvam a tarefa de modo espontâneo, sem o apoio ou acompanhamento da professora.

A leitura da tarefa pela professora também é uma ação evidenciada por 16 grupos de FP (QUADRO 2).

Quadro 2 - Leitura do enunciado da tarefa, focalizando seus principais aspectos.

\begin{tabular}{|l|l|}
\hline \multicolumn{1}{|c|}{ Evidências } & $\begin{array}{l}\text { Grupos } \\
\text { de FP e } \\
\text { NR }\end{array}$ \\
\hline $\begin{array}{l}\text { [...] ela descreve o que está sendo proposto e de que } \\
\text { maneira deve ser abordada a tarefa, ou seja, observar se } \\
\text { existe ou não alguma relação entre as figuras. (G2, E, } \\
\text { 03/07/17, Ep. 1 - Q2). }\end{array}$ & G3 (E), \\
G4 (E), \\
G5 (E),
\end{tabular}




\begin{tabular}{|c|c|}
\hline $\begin{array}{l}\text { [...] ela vai chamando a atenção dos alunos para a tarefa, } \\
\text { para que eles prestem mais atenção nela, para que eles } \\
\text { possam entender melhor o que se pede nas questões. Para } \\
\text { isso, ela fala bastante dos colares, das relações que tem } \\
\text { entre cada uma das figuras de cada colar e o que ocorre de } \\
\text { um para o outro. (G18, E, 03/07/17, Ep. } 1 \text { - Q2). }\end{array}$ & $\begin{array}{l}\text { G6 (D), } \\
\text { G7 (E), } \\
\text { G8 (D), } \\
\text { G9 (E), } \\
\text { G11 (E), } \\
\text { G12 (D), }\end{array}$ \\
\hline $\begin{array}{l}\text { É importante para a iniciação das atividades, para que os } \\
\text { alunos tenham um ponto de partida para que possam } \\
\text { começar a responder as questões e também para que o } \\
\text { aluno com dificuldade não tenha um entendimento muito } \\
\text { distante do que se pede. (G20, } \mathrm{P}, 03 / 07 / 17, \text { Ep. } 1 \text { - Q2). }\end{array}$ & $\begin{array}{l}\text { G13 (D), } \\
\text { G14 (D), } \\
\text { G16 (D), } \\
\text { G18 (E), } \\
\text { G20 (P). } \\
\text { (16 } \\
\text { grupos) }\end{array}$ \\
\hline
\end{tabular}

As explicações e previsões de alguns FP sobre a leitura da tarefa revelam a compreensão do modo pelo qual a professora desenvolve essa ação tendo em vista o foco dos alunos para os principais aspectos da tarefa, à iniciativa de resolvê-la, sobretudo dos que possam ter mais dificuldades, bem como torná-los conscientes do conteúdo/objetivo central da atividade (WELLS, 2004; CYRINO; OLIVEIRA, 2016).

Embora tenha sido uma ação momentânea da professora, a sua indicação de um tempo específico para o desenvolvimento da tarefa é destacada por 13 grupos de FP.

Quadro 3 - Indicação de um tempo para o desenvolvimento da tarefa

\begin{tabular}{|l|l|}
\hline Evidências & Grupos \\
& de $\quad$ FP e \\
NR
\end{tabular}




\begin{tabular}{|c|c|}
\hline $\begin{array}{l}\text { [...] é importante ela mencionar que terá um bom tempo } \\
\text { para realizar a atividade, isso faz com que os alunos não se } \\
\text { apavorem, fazendo a atividade de qualquer jeito. Mas } \\
\text { também [...], permite aos alunos a organização e a } \\
\text { distribuição das atividades em grupo, pois assim eles sabem } \\
\text { que precisam se organizar e se ajudarem para que possam } \\
\text { cumprir esse objetivo. (G4, } \mathrm{P}, 03 / 07 / 17, \text { Ep. } 1 \text { - Q2). }\end{array}$ & $\begin{array}{l}\text { G1 (E), } \\
\text { G4 (P), } \\
\text { G5 (D), } \\
\text { G6 (D), } \\
\text { G7 (D), } \\
\text { G8 (D), }\end{array}$ \\
\hline $\begin{array}{l}\text { Determinar um tempo para resolver a atividade faz com que } \\
\text { os alunos se concentrem mais no que estão fazendo, tendo } \\
\text { em vista que a professora estará passando em todos os } \\
\text { grupos para acompanhar o desenvolvimento da atividade. } \\
\text { Também é bom para aqueles que forem terminando não se } \\
\text { dispersarem. (G14, } \mathrm{P}, 03 / 07 / 17, \text { Ep. } 1 \text { - Q2). }\end{array}$ & $\begin{array}{l}\text { G9 (P), } \\
\text { G10 (D), } \\
\text { G11 (E) } \\
\text { G14 (P), } \\
\text { G16 (D), } \\
\text { G18 (E) }\end{array}$ \\
\hline $\begin{array}{l}\text { [...] para que os alunos aprendam a se organizar para } \\
\text { conseguir cumprir a tarefa no tempo dado (G11, E, } \\
01 / 10 / 14, \mathrm{Ep} .1-\mathrm{Qb}) .\end{array}$ & G20 (E). \\
\hline $\begin{array}{l}\text { [...] faz com que eles também percebam e se preparem para } \\
\text { outra etapa da aula. (G20, E, 03/07/17, Ep. } 1 \text { - Q2). }\end{array}$ & \\
\hline
\end{tabular}

Os dados evidenciam que os FP consideram essa ação da professora significativa, uma vez que preveem que ela pode contribuir à organização e à concentração dos alunos não só para a realização da tarefa, mas também às próximas fases da aula.

Ao observarem o vídeo, 11 grupos identificam que a professora, por meio de questões, pretende suscitar e tirar algumas dúvidas dos alunos.

Quadro 4 - Suscitar e tirar algumas dúvidas dos alunos

\begin{tabular}{|l|l|}
\hline Evidências & Grupos \\
& de FP e \\
NR
\end{tabular}




\begin{tabular}{|l|l|}
\hline $\begin{array}{l}\text { [...] nesse momento muitas dúvidas podem surgir, e isso faz } \\
\text { com que as dúvidas questionadas por alguns alunos ajudem }\end{array}$ & G4 (E), \\
os demais colegas a compreender o que deverá ser feito. & G5 (D), \\
(G4, E, 03/07/17, Ep. 1 - Q2). & G6 (D), \\
\cline { 1 - 2 } [...] esclarecer as dúvidas dos alunos pode fazer com que & G7 (D), \\
eles comecem a pensar numa forma de resolução de forma & G8 (D), \\
coerente à tarefa. (G12, E, 03/07/17, Ep. 1 - Q2). & G9 (D), \\
\cline { 1 - 1 } & G11 (E), \\
[...] a professora tira qualquer dúvida dos alunos. (G13, D, & G13 (D), \\
$01 / 10 / 14$, Ep. 1 - Q1). & G14 (D). \\
& (11 \\
\end{tabular}

Esse aspecto é percebido por alguns FP como uma forma de mobilizar o pensamento dos alunos em direção ao objetivo matemático da tarefa. Porém, alguns grupos parecem interpretar que a professora irá tirar quaisquer dúvidas que possam surgir dos alunos, inclusive sobre o modo de resolver a tarefa, retirando-lhes, com isso, a sua autonomia na criação de uma estratégia matemática (QUADRO 4).

O esclarecimento feito pela professora aos alunos de que será preciso justificar a resposta de cada questão da tarefa é uma ação denotada por 11 grupos de FP.

Quadro 5 - Apontar a necessidade de escrever justificativas as suas respostas

\begin{tabular}{|l|l|}
\hline \multicolumn{1}{|c|}{ Evidências } & $\begin{array}{l}\text { Grupos } \\
\mathrm{de} \mathrm{FP} \mathrm{e} \\
\mathrm{NR}\end{array}$ \\
\hline $\begin{array}{l}\text { [...] como se trata de uma tarefa na qual não há uma única } \\
\text { maneira de resolver, o aluno é conduzido a selecionar e } \\
\text { analisar os dados que acha importante, colocar no papel } \\
\text { para então tirar conclusões. (G2, } \mathrm{P}, 03 / 07 / 17, \text { Ep. 1- Q2). }\end{array}$ & \\
\cline { 1 - 2 } &
\end{tabular}




\begin{tabular}{|c|c|}
\hline $\begin{array}{l}\text { nossos raciocínios para o papel podemos aprender mais, } \\
\text { pois estamos registrando os pensamentos e talvez passar de } \\
\text { uma linguagem natural [verbal] para simbólica [algébrica]. } \\
\text { Possibilitando também que outros indivíduos possam } \\
\text { acompanhar nossas ideias com clareza. (G4, } \mathrm{P}, 03 / 07 / 17 \text {, } \\
\text { Ep. } 1 \text { - Q2). }\end{array}$ & $\begin{array}{l}\text { G2 (P), } \\
\text { G3 (E), } \\
\text { G4 (P), } \\
\text { G6 (D), } \\
\text { G7 (D), } \\
\text { G8 (D), } \\
\text { G9 (E), } \\
\text { G10 (D), } \\
\text { G16 (D), } \\
\text { G18 (P), }\end{array}$ \\
\hline
\end{tabular}

Ao discorrerem sobre a importância de a professora solicitar aos alunos que justifiquem as suas respostas, alguns FP manifestam (re)conhecê-la como uma ação que vai além de um mero lembrete. O Quadro 5 apresenta previsões dos FP sobre o potencial da elaboração de justificativas escritas pelos alunos que sejam compreensíveis a outros leitores ao processo de organização do pensamento e aperfeiçoamento da linguagem, bem como às capacidades de discutir, refletir e tirar conclusões.

O fato de a professora deixar claro que irá às carteiras auxiliar os grupos após ter esclarecido o que é esperado deles, é um aspecto difícil de ser percebido em sua totalidade, mas que se sobressai à visão de cinco grupos de FP (QUADRO 6). 
Quadro 6 - Explicitar o papel de cada um no processo de desenvolvimento da tarefa

\begin{tabular}{|c|c|}
\hline Evidências & $\begin{array}{l}\text { Grupos } \\
\text { de FP e } \\
\text { NR }\end{array}$ \\
\hline $\begin{array}{l}\text { [...] essa atitude da professora faz com que percebemos que } \\
\text { ela se preocupa com os alunos [...]. Para que esse aluno } \\
\text { não fique perdido, nem se sinta menos capaz que os outros } \\
\text { durante a realização das atividades. (G4, } \mathrm{P}, 03 / 07 / 17 \text {, Ep. } 1 \\
\text { - Q2). }\end{array}$ & \\
\hline $\begin{array}{l}\text { É importante que os alunos saibam o que se espera deles no } \\
\text { desenvolvimento da tarefa, a partir de instruções inicias } \\
\text { sobre o que devem estar atentos e sobre o tempo previsto. } \\
\text { (G3, } \mathrm{P}, 01 / 10 / 14, \mathrm{Ep} .1-\mathrm{Q} 2) .[. . .] \text { o objetivo desse primeiro } \\
\text { momento é que os alunos compreendam a tarefa para que } \\
\text { possam começar a pensar na sua resolução. (G3, } \mathrm{P} \text {, } \\
01 / 10 / 14, \mathrm{Ep} .1-\mathrm{Q} 3) \text {. }\end{array}$ & $\begin{array}{l}\text { G3 (P), } \\
\text { G4 (P), } \\
\text { G6 (D), } \\
\text { G9 (P), } \\
\text { G14 (D). }\end{array}$ \\
\hline $\begin{array}{l}\text { Para que os alunos não fiquem dispersos, para que não se } \\
\text { sintam desmotivados [...], a professora deixa bem claro o } \\
\text { que ela espera dos alunos, como, por exemplo, que } \\
\text { justifiquem o seu raciocínio a cada questão e que eles terão } \\
\text { um tempo para isso. Como ponto chave sobre seu papel [a } \\
\text { professora] também fala da disponibilidade dela } \\
\text { desenvolvimento da tarefa] [...]. (G9, P, 01/10/14, Ep.1 - } \\
\text { Q2). }\end{array}$ & \\
\hline
\end{tabular}

No Quadro 6, a ação da professora de explicitar o seu papel na próxima fase da aula junto aos esclarecimentos e solicitações iniciais, apresenta-se como uma síntese elaborada pelos FP sobre a fase inicial da aula. Um processo de raciocínio exigente e, portanto, desenvolvido por cinco dos 17 grupos de FP. Assim, de modo geral, tais grupos interpretam o esclarecimento do papel de cada um, como significativo para 
encorajar os alunos e engajá-los à proposta da atividade, a partir da compreensão do que é pedido, assim como ter clareza das formas de participação dos diferentes agentes na aula de Matemática na perspectiva do Ensino Exploratório (OLIVEIRA; MENEZES; CANAVARRO, 2013; CYRINO; TEIXEIRA, 2016).

\section{CONCLUSÕES}

O objetivo central desse estudo consistiu em analisar a visão profissional de 36 FP sobre as ações docentes realizadas para promover o engajamento inicial dos alunos em uma aula de Matemática na perspectiva do Ensino Exploratório. Por meio de tópicos sintetizadores, os resultados evidenciam seis aspectos da proposição e apresentação da tarefa que se sobressaem à visão dos FP - i) formação de grupos; ii) leitura do enunciado da tarefa; iii) indicação de um tempo para o desenvolvimento da tarefa; iv) suscitar e tirar algumas dúvidas dos alunos; v) apontar a necessidade de escrever justificativas as respostas da tarefa; e vi) explicitar o papel de cada um no processo de desenvolvimento da tarefa. Além disso, os FP revelam perceber os significados didático-pedagógicos que subjazem tais aspectos, na medida em que eles são manifestados pela sua capacidade de perpassar diferentes dimensões de raciocínio (descrição, explicação e previsão) sobre os eventos (re)conhecidos no vídeo.

Tais resultados evidenciam que, a análise orientada da fase inicial da aula, muitas vezes despercebida, pode contribuir para uma discussão mais aprofundada e alargada dos elementos nucleares que orientam o processo de aprendizagem dos alunos no Ensino Exploratório na perspectiva dialógica, tais como o engajamento, a colaboração, a comunicação oral e escrita, bem como a tomada de consciência da atividade de inquiry a ser desenvolvida na aula (WELLS, 2002; 2004; HIEBERT, 2003; CYRINO; OLIVEIRA, 2016).

No decorrer do Estágio Curricular Supervisionado, não é raro os licenciandos apontarem a falta de engajamento dos alunos com a tarefa ou com a aula de Matemática como uma problemática frequente na etapa de observação/co-participação e, em consequência, como um desafio docente a ser enfrentado por eles na etapa da regência. Nesse sentido, a discussão dessa questão merece mais atenção na formação inicial, 
sobretudo, a partir de um olhar sobre o engajamento dos alunos como um processo que pode ser colocado em (des)envolvimento pelo professor. Nós entendemos que essa problemática abrange diversos elementos que podem ir além das ações docentes, todavia, a clareza dessa complexidade não prescinde o desenvolvimento da visão profissional do papel do professor nesse processo.

Outro ponto a ser considerado é a importância do caso multimídia no contexto de formação de professores, devido às oportunidades de aprendizagem profissional oferecidas aos FP por meio da exploração de artefatos da prática docente, como a tarefa matemática, o plano de aula, os áudios com as intenções da professora antes da aula, bem como, aqueles que foram destacadas neste trabalho, referentes às possibilidades audiovisuais do vídeo junto às especificidades de seu conteúdo sobre a prática pedagógica na perspectiva do Ensino Exploratório.

Cabe salientar também que, assim como indicado nas conclusões do estudo de Sherin e van Es (2009), quando a atenção seletiva dos FP direciona-se somente para as ações do professor, seus raciocínios tendem a ser mais descritivos ou a apresentar explicações mais superficiais. Enquanto que, quando os FP são solicitados a escreverem sobre a importância das ações da professora (Questão 2 do Episódio 1), sua atenção seletiva orienta-se também para o que essas ações mobilizaram ou poderão mobilizar nos alunos. Essa evidência pode ser associada ao modo de raciocinar explicitado pelos FP que engloba também as consequências ou resultados das ações do professor à atividade que venha a ser desenvolvida pelos alunos.

\section{REFERÊNCIAS}

ARTIGUE, M.; BLOMHØJ, M. Conceptualizing inquiry-based education in mathematics. ZDM Mathematics Education, v. 45, n. 6, p. 797-810, 2013.

BLOMBERG, G. et al. Five research based heuristics for using video in pre-service teacher education. Journal of Educational Research Online, v. 5, n. 1, p. 90-114, 2013. 
BORKO, $\mathrm{H}$. et al. Using video representations of teaching in practice-based professional development programs. ZDM Mathematics Education. v. 43, p. 175-187, 2011.

BRASIL. Ministério da Educação. Conselho Nacional de Educação. Parecer CNE/CP n. 9, de 08 de maio de 2001. Diretrizes Curriculares Nacionais para a Formação de Professores da Educação Básica, em nível Superior, curso de licenciatura, de graduação Plena. Brasília, DF, 2001a. Disponível em: <http://portal.mec.gov.br/cne/arquivos/pdf/009.pdf>. Acesso em: 23 set. 2016.

CHAPMAN, O.; HEATER, B. Understanding change through a high school mathematics teacher's journey to inquiry-based teaching. Journal of Mathematics Teacher Education, v.13, n.6, p. 445-458, 2010.

CHAPMAN, O. Mathematics teachers' learning through inquiry. Sisyphus, v. 1, n. 3, p.122-150, 2013.

CHARMAZ, K. A construção da teoria fundamentada: guia prático para análise qualitativa. Tradução de Joice E. Costa. Porto Alegre: Artmed, 2009. Tradução de: Constructing Grounded Theory: a practical guide through qualitative analysis.

CYRINO, M. C. C. T.; OLIVEIRA, H. Casos multimídia sobre o ensino exploratório na formação de professores que ensinam matemática. In: CYRINO, M. C. C. T. (Org.). Recurso multimídia para a formação de professores que ensinam matemática: elaboração e perspectivas. Londrina: EDUEL, 2016. p. 19-32.

CYRINO, M. C. C. T.; TEIXEIRA, B. R. O ensino exploratório e a elaboração de um framework para os casos multimídia. In: CYRINO, Márcia C. C. T. (Org.). Recurso multimídia para a formação de professores que ensinam matemática: elaboração e perspectivas. Londrina: EDUEL, 2016. p. 81-100.

ERICKSON, F. Qualitative methods in research on teaching. In: WITTROCK, M. C. (Ed.). Handbook of research on teaching. Nova Iorque: MacMillan, 1986. p. 119-161.

FIORENTINI, D.; NACARATO, A. M.; PINTO, A. R. Saberes da experiência docente em Matemática e Educação Continuada. Quadrante Revista teórica e de investigação, Portugal, 8 (1-2), p. 33-60. 1999. 
GÓES, M. C. R. A natureza social do desenvolvimento psicológico. Cadernos CEDES, Campinas, n. 24, p. 21-29, 2000.

SILVA, L. H. de A. S.; GÜLliCH, R. I. da C.; FERREIRA, F. C. O estágio supervisionado em prática de ensino de ciências e biologia: (des)construção de imagens do ser professor?. In: GONÇALVES, A. V.; PINHEIRO, A. S.; FERRO, M. E. (org.). Estágio Supervisionado e Práticas Educativas: Diálogos interdisciplinares. Dourados (MS): Editora UEMS. 2011. p. 269-284.

HIEBERT, J. What research says about the NCTM Standards. In: KILPATRICK, J.; MARTIN; G. W.; SCHIFTER, D. (Eds.). A Research Companion to Principles and Standards for school mathematics. Reston, Virginia: National Council of Teachers of Mathematics, 2003. p. 5-23.

KERSTING, N. et al. Teachers' analyses of classroom video predict student learning of mathematics: Further explorations of a novel measure of teacher knowledge. Journal of Teacher Education, v. 61, n.1-2, p. 172-181, 2010.

KRAINER, K. Teams, communities \& networks. Journal of Mathematics Teacher Education, Netherlands, v. 6, n. 2, p. 93-105, jun. 2003.

MESTRE, C.; OLIVEIRA, H. A co-construção da generalização nas discussões coletivas: Um estudo com uma turma do 4. ${ }^{\circ}$ ano. Quadrante, v. 21, n. 2, p. 111-138, 2012.

OLIVEIRA, H.; CYRINO, M., C. C. T. Developingknowledgeofinquirybasedteachingby analysing a multimedia case: Onestudywithprospectivemathematicsteachers. Sisyphus, v. 1, n. 3, p. 214-245, 2013.

OLIVEIRA, H.; MENEZES, L.; CANAVARRO, A. P. Conceptualizando o ensino exploratório da Matemática: Contributos da prática de uma professora do $3 .^{\circ}$ ciclo para a elaboração de um quadro de referência. Quadrante, v. 22, n. 2, p. 29-53, 2013.

PEDRO, I. J. C. R. Das sequências à proporcionalidade direta: uma experiência de ensino no 6. ${ }^{\circ}$ ano de escolaridade. 2013. 104 f. Dissertação (Mestrado em Educação) Instituto de Educação, Universidade de Lisboa, Lisboa. 
PONTE, J. P. Gestão Curricular em matemática. In: GTI (Ed.). O professor e o desenvolvimento curricular. Lisboa: Associação de Professores de Matemática, 2005. p. 11-34.

SANTAGATA, R.; ZANNONI, C.; STIGLER, J. The role of lesson analysis in preservice teacher education: An empirical investigation of teacher learning from a virtual video-based field experience. Journal of Mathematics Teacher Education, v. 10, n. 2 , p. 123-140, 2007.

SCHÄFER, S.; SEIDEL, T. Noticing and reasoning of teaching and learning components by preservice teachers. Journal for Educational Research Online, v. 7, n. 2, p. 34-58, 2015.

SEIDEL, T.; STÜRMER, K. Modeling the structure of professional vision in preservice teachers. American Educational Research Journal, v. 51, n. 4, p. 739-771, 2014.

SHERIN, M. G. The development of teachers' professional vision in video clubs. In: GOLDMAN, R.; PEA, R.; BARRON, B.; DERRY, S. J. (Eds.). Video research in the learning sciences. Mahwah, NJ: Lawrence Erlbaum, 2007. p. 383-395.

SHERIN, M.G.; VAN ES, E.A. Effects of Video Club Participation on Teachers' Professional Vision. Journal of Teacher Education, v. 60, n. 1, p. 20-37, nov. 2009.

STEIN, M. K. et al. Orchestrating productive mathematical discussions: Helping teachers learn to better incorporate student thinking. Mathematical Thinking and Learning, v. 10, n. 4, p. 313-340, 2008.

STEIN, M. K.; SMITH, M. S. Tarefas matemáticas como quadro para a reflexão: Da investigação à prática. Tradução de Alunos de mestrado em Educação Matemática da FCUL. (Artigo original publicado em 1998). Educação e Matemática, n.105, p. 22-28, 2009. Tradução de: Mathematical tasks as a framework for reflection: From research to practice.

VAN ES, E.; SHERIN, M. Learning to notice: Scaffolding new teachers' interpretations of classroom interactions. Journal of Technology and Teacher Education, v. 4, n. 10, p. 571-596, 2002. 
. Mathematics teachers "learning to notice" in the context of a video club.

Teaching and Teacher Education, v. 24, n.2, p. 244-276, 2008.

WELLS, G. Learning and teaching for understanding: The key role of collaborative knowledge building. Social Constructivist Teaching, v. 9, p. 1-41, 2002.

Dialogic inquiry: Towards a sociocultural practice and theory of education. Cambridge: Cambridge University Press, 2004. 